\title{
Participação on-line e off-line no Brasil: relações e condicionantes
}

Ednaldo Aparecido Ribeiro

Universidade Estadual de Maringá (UEM) e Universidade Federal do Paraná (UFPR)

Julian Borba

Universidade Federal de Santa Catarina (UFSC)

Jaqueline Resmini Hansen

Universidade Federal de Minas Gerias (UFMG)

Nas últimas décadas, a democracia se consolidou como a melhor configuração governamental, entretanto, tem se falado em uma crise da democracia representativa que se expressa numa queda nas modalidades tradicionais de participação e na confiança nas instituições políticas. Concomitante a esse processo, emergem as tecnologias digitais, que, por meio da internet, criam o ciberespaço, apresentando uma nova via para o ativismo político e social. Instigados por esse contexto, pesquisadores do comportamento político têm analisado quais características comportamentais, sociais e demográficas influenciam no ciberativismo, questionando se são as mesmas que condicionam as ações presenciais. Alguns autores concluíram que indivíduos que já participam são mais propensos ao ciberativismo, bem como a rede pode fortalecer as modalidades de protesto. Além disso, pesquisas apontam a centralidade do interesse por assuntos políticos, do acesso à informação, da educação e, em alguns casos, da idade na caracterização dos ativistas digitais. Diante desse quadro internacional, a presente pesquisa questiona qual o perfil do ativista on-line brasileiro. Para tanto, se utiliza do banco de dados do Latin American Public Opinion Project (Lapop) do ano de 2012.

Palavras-chave: participação política, democracia, internet, comportamento humano

[Artigo recebido em 14 de outubro de 2015. Aprovado em 13 de julho de 2016.] 


\section{Participación online e offline en Brasil: relaciones y condicionantes}

En las últimas décadas, la democracia se ha consolidado como la mejor configuración de gobierno, sin embargo, se ha hablado en una crisis de la democracia representativa que se expresa en una caída en los modos tradicionales de participación y en la confianza en las instituciones políticas. Paralelamente a este processo se hacen las nuevas tecnologías digitales, que crean el ciberespacio de internet, presentando un nuevo camino hacia el activismo político y social. Instigados por este contexto, investigadores del comportamiento político han analizado cuáles son las características de comportamiento, sociales y demográficas que influyen en el ciberactivismo, cuestionando si son las mismas que afectan a las actividades presenciales. Algunos autores concluyeron que las personas que ya participan son más propensas al activismo cibernético, así la red puede fortalecer las modalidades de protesta. Además, la investigación indica la centralidad de interés en temas políticos, del acceso a la información, de la educación y, en algunos casos, de la edad sobre la caracterización de los activistas digitales. Ante este marco internacional, la presente investigación cuestiona cuál es el perfil del activista digital brasileño. Para ello, utilizamos la base de datos de Latin American Public Opinion Project (Lapop) de 2012.

Palabras clave: participación política, democracia, internet, comportamiento humano

\section{Online and offline participation in Brazil: relationships and conditionants}

In the last decades, democracy has consolidated itself as the best governmental configuration, however, it has been spoken about a crisis of representative democracy that is expressed in a decline in traditional forms of participation and trust in political institutions. Concomitant to this process are the digital technologies that, through the internet, create cyberspace, presenting a new avenue for political and social activism. Instigated by this context, researchers of political behavior has analyzed what behavioral, social and demographic characteristics influence cyber-activism questioning whether they are the same that condition the offline actions. Some authors have concluded that individuals who already participate are more prone to cyber-activism, and the network can strengthen protest modalities. In addition, research points to the centrality of interest in political issues, access to information, education and, in some cases, age in the characterization of digital activists. Given this international framework, this research questions the profile of the Brazilian online activist. For this purpose, the Latin American Public Opinion Project - LAPOP database of the year 2012 is used.

Keywords: political participation, democracy, internet, human behavior 


\section{Introdução}

A década de 1990 e anos 2000 são marcados por mudanças no padrão de cidadania política nas democracias ocidentais. A base dessas transformações, que alguns autores têm relacionado à emergência de uma cidadania crítica (NoRRIS, 2001), é uma combinação de forte desencantamento com as principais instituições democráticas (partidos e parlamentos) e disseminação de modalidades de protesto e ação direta.

Característica desse período também é a popularização da internet, acontecimento tecnológico tão significativo quanto as mudanças ocorridas no âmbito da cidadania política, já que revolucionou o modo como os indivíduos se comunicam, ao retirar o monopólio dos meios de comunicação na produção de notícias e informações e derrubar algumas barreiras no acesso. Atualmente são três bilhões de indivíduos conectados, o que corresponde a 40,4\% da população mundial (INTERNATIONAL TELECOMMUNICATION UNION, 2014).

Apesar do contingente significativo de "desconectados", evidenciando enorme desigualdade no acesso, é inegável que as novas tecnologias que compõem essa rede de computadores ampliaram significativamente a diversidade de conteúdos, uma vez que suas publicações não passam necessariamente pelo crivo de editores, como ocorre na televisão, jornais e revistas. Em decorrência disso, qualquer indivíduo conectado pode se tornar um produtor de informações, usando o Youtube, o Twitter ou Facebook para divulgar notícias ou opiniões. Além disso, é preciso destacar o caráter interativo da web, ao viabilizar a comunicação relativamente direta entre o remetente e o receptor da informação.

A ampliação da autonomia na produção de conteúdos e a multiplicação das redes de interação geradas por essa nova tecnologia motivam indagações sobre seus impactos nas formas como os cidadãos interagem com o mundo político. Nesse sentido, este artigo apresenta resultados de pesquisa que procurou avaliar empiricamente o potencial participativo da internet no contexto brasileiro, quais os condicionantes do ativismo on-line, bem como as possíveis relações entre formas de ciberativismo e modalidades presenciais de ação. A questão central que procuramos responder é se as supostas facilidades proporcionadas pela rede mundial de computadores para a mobilização e engajamento político estariam favorecendo o envolvimento de indivíduos não mobilizados no ativismo presencial, contribuindo assim para a avaliação concreta do potencial democratizador das novas mídias.

Guiado pelos objetivos supracitados, o artigo possui mais três seções além desta. A primeira apresenta um debate sobre as modalidades e os condicionantes da participação política, a segunda discute as particularidades do ativismo on-line, 
e a terceira analisa o cenário brasileiro a partir dos dados produzidos pelo Latin American Public Opinion em sua edição de 2012, quando pela primeira e única vez foram inseridas questões relativas ao ativismo on-line. Por fim, são apresentadas conclusões provisórias sobre a relação entre o ativismo on-line e presencial, bem como sobre os efeitos mobilizadores da web no contexto nacional.

\section{Participação política}

Democracia e participação política são conceitos intimamente relacionados. Toda concepção do que seria um governo democrático, até mesmo a mais minimalista, assume a necessidade do envolvimento dos cidadãos, ainda que apenas no processo eleitoral (NORRIS, 2002; VAN Deth, 2001; Verba; Schlozman; BRAdY, 1995). Desde a década de 1940, com a emergência de pesquisas de opinião pública e estudos comportamentalistas em Ciência Política, pesquisadores vêm debatendo o fenômeno participativo, sendo o trabalho desenvolvido por Milbrath na década de 1960 o pioneiro na proposição de uma definição que, naquele momento, se limitava aos atos ligados ao momento das eleições e às suas atividades correlatas (MilBTATH, 1965).

Concepções imediatamente posteriores entenderam a participação basicamente como ações que visam influenciar instituições representativas, principalmente no que se refere à distribuição de bens públicos e à atuação de formuladores e gestores de políticas. Nesse debate inicial, as diferentes modalidades eram divididas e classificadas em razão da sua complexidade, iniciando com as mais simples, como votar, passando pela filiação partidária e, por fim, chegando a ações com alto nível de complexidade, como candidatar-se a um cargo eletivo. É importante destacar, portanto, que as primeiras delimitações do conceito desconsideravam ações fora do âmbito institucional da democracia (BORBA, 2012a; RIBEIRO; BORBA, 2011; RIBEIRO; Borba, 2015; VAN DETH, 2001; Verba; SCHLOZMAN; BRADY, 1995).

A década de 1970 foi rejuvenescedora para essa discussão, ao trazer a ampliação do conceito e dos esforços classificatórios. Exemplar dessa nova fase é a obra Political Action (1979), de Samuel H. Barnes, Max Kaase e colaboradores. Nessa obra, os autores propuseram que os atos de protesto não são sinônimos de instabilidade democrática, mas sim importantes canais de expressão cidadã e, consequentemente, deveriam estar presentes nas análises das modalidades de ação política. Com essa incorporação, sugeriram a divisão das modalidades em convencionais e não convencionais. As primeiras englobariam atos relacionados com os processos eleitorais, tais como voto, atividade de campanha, contato personalizado, doação de dinheiro para campanhas e discussão sobre política. 
As não convencionais, por sua vez, reuniriam atos de contestação como participar de manifestações, protestos, bloqueio de ruas e tráfego, boicotes, greves e abaixo-assinado.

Para essa perspectiva, os indivíduos atuariam levando em consideração os custos, benefícios e habilidades que diferentes repertórios exigem, fazendo com que a participação ocorra em um continuum (DALTON; VAN SICKLE, 2005; NORRIS, 2001; Ribeiro; Borba, 2015; Rennó, 2001; Verba; SChlozman; Brady, 1995).

Após a incorporação das modalidades de protesto como formas de ação política legítimas e fortalecedoras da democracia, o desenvolvimento seguinte na agenda de pesquisas sobre participação passou pela diluição das fronteiras entre o social e o político. Verba, Schlozman e Brady (1995), em Voice and Equality, demonstraram que a participação em esferas não estritamente políticas (a participação social) também é uma ação política e vice-versa. Atos participativos não se dirigiriam somente ao governo, mas também à sociedade, procurando influenciar tanto as decisões políticas como os estilos de vida. Esses autores também foram fundamentais no desenvolvimento de um modelo explicativo da participação, identificando três conjuntos fundamentais de condicionantes do engajamento cívico: recursos, motivação e recrutamento. Inicialmente esses autores definem a participação como um ato voluntário, por meio do qual indivíduos utilizam diferentes táticas, de acordo com suas capacidades e motivações, para colocar sua voz no espaço público, de preferência de forma clara e alta (VERBA; SCHLOZMAN; BRADY, 1995).

As contribuições de Inglehart e Welzel (2009) também são relevantes para a compreensão da participação em termos mais atualizados, já que propõem a classificação das modalidades a partir do padrão de relação entre cidadãos e as elites políticas estabelecido no curso da ação. Assim, modalidades direcionadas ao governo e que passam por organizações hierarquizadas, como o engajamento partidário, seriam chamadas de elite directed. Modalidades mais diretas e orientadas pelo desejo de contestação, como protestos, manifestações e boicotes, comporiam o grupo das ações elite challenging (INGLEHART; WELZEL, 2009; RIBEIRO, 2011).

Pippa Norris (2002, 2007) também se insere nesse esforço classificatório, afirmando que, apesar de ter ocorrido uma queda nas formas convencionais de participação e uma ascensão das não convencionais, as últimas não estão substituindo as primeiras. A autora defende que o ativismo político passa por um processo de reinvenção que combina modalidades eleitorais com ações de protesto. A partir disso, propõe uma nova nomenclatura para designar as modalidades de ação no espaço público que leva em consideração a sua orientação. Portanto, teríamos ações citizen oriented e cause oriented, sendo as primeiras relativas aos repertórios tradicionais e destinadas a influenciar a democracia diretamente por 
meio do voto ou indiretamente, via filiação partidária, trabalho de campanha e contato com agentes políticos. Os repertórios orientados para a causa, por sua vez, envolvem modalidades de protesto, focalizando questões políticas específicas e tendo diversos alvos, dentro e fora da arena eleitoral. Nesse sentido, as fronteiras entre o político e o social se tornam cada vez mais tênues e fluídas.

Esse debate classificatório também gera uma importante discussão sobre o relacionamento existente entre as distintas modalidades. Alguns autores defendem que os atos participativos não são excludentes, e que os cidadãos atuariam em função da centralidade de repertórios e ativariam todos os que estão disponíveis, propondo assim a hipótese da convergência entre modalidades. Outros, entretanto, defendem que a crescente crise que assola a democracia representativa leva os indivíduos a abandonarem as modalidades tradicionais de ação em favor das modalidades de protesto, afirmando assim a tese da divergência entre os repertórios de ação e prognosticando o declínio da participação tradicional (BORBA; RIBEIRO, 2010; BorbA, 2012a; INGLEHART; Welzel, 2009; NoRRIS, 2001, 2002, 2007; RIBEIRO; BORBA, 2011, 2012, 2015).

$\mathrm{Na}$ base das pesquisas sobre as classificações e testes das hipóteses da convergência ou divergência, estão investigações empíricas que têm procurado identificar quais fatores influenciariam o engajamento político dos cidadãos. Aspectos estruturais do Estado e da sociedade, como o desenvolvimento socioeconômico e as instituições políticas e sociais; e atributos individuais ligados a recursos materiais e motivações individuais têm sido combinados de diferentes formas em distintas pesquisas para entender os condicionantes do ativismo político (BorbA; RIBEIRO, 2010; BorbA, 2012a; INGLEhART; WelZEL, 2009; NORRIS, 2002).

Os estudos que enfatizam as estruturas econômicas e políticas nacionais ou regionais defendem a existência de uma forte relação entre desenvolvimento socioeconômico e participação política. Para essas vertentes, os processos de modernização da sociedade elevam os níveis de escolarização, ajudam a desenvolver a consciência política e levam ao engajamento cívico. Além disso, diferentes arranjos institucionais fomentariam ou dificultariam de formas distintas o engajamento cívico, fornecendo estruturas de oportunidades mais ou menos favoráveis (INGLEHART; WELZEL, 2009; NORRIS, 2002; RENNó, 2003).

No campo dos estudos que enfatizam condicionantes individuais, a perspectiva mais recorrente tem sido a desenvolvida por Verba, Schlozman e Brady (1995), conhecida como modelo do voluntarismo cívico. Para esses autores, o engajamento seria impactado por recursos sociais (tempo, dinheiro e habilidades cívicas), motivações subjetivas e inserção em redes de recrutamento. A ideia de recurso é central, pois ela complementa o caráter voluntário da ação, já que, segundo 
os pesquisadores, as pessoas não participam "because they can't; because they don't want to; because nobody ask" (VERBA; SCHLOzMAN; BRADY, 1995, p. 269). Os indivíduos se mobilizam politicamente quando possuem os recursos necessários, quando estão interessados ou motivados psicologicamente na participação e quando são convidados (ou recrutados).

Esse modelo foi fundamental para o desenho da pesquisa cujos resultados apresentamos neste artigo, já que a questão geral que nos interessa diz respeito ao suposto impacto mobilizador da rede mundial de computadores em termos políticos. Esse impacto seria operado principalmente em razão da redução dos custos da informação e também pela possibilidade da multiplicação das redes de recrutamento com a conectividade proporcionada pelas novas plataformas de comunicação. Nos termos do modelo do voluntarismo cívico, a internet poderia favorecer o engajamento pela redução dos custos da participação, em termos de tempo e dinheiro, além de multiplicar os possíveis recrutadores, principalmente em razão da expansão das redes sociais digitais. Verificações dessas hipóteses foram conduzidas por meio da identificação do perfil dos ativistas on-line e também através da análise das relações existentes entre as modalidades on-line e presenciais. Antes de apresentar os resultados desses testes, na próxima seção sintetizamos brevemente a literatura que tem se debruçado sobre essas possíveis inter-relações entre o ativismo na rede e fora dela.

\section{Internet e engajamento político}

A agenda de pesquisa sobre a relação entre novas tecnologias e ativismo político tem sido marcada por expressiva diversidade interna. Entre estudos fortemente orientados por modelos normativos (otimistas, pessimistas ou céticos) e abordagens empíricas que procuram aplicar modelos já consolidados no estudo do comportamento político, a multiplicidade de perspectivas é significativa. Nossa intenção nesta seção não é listar exaustivamente essas abordagens, mas apenas apontar em linhas gerais quais são as orientações dominantes dessa agenda crescente de investigações.

Começando por abordagens orientadas por preceitos normativos, os estudiosos chamados de ciberotimistas argumentam que a internet, ao criar uma nova estrutura de comunicação, cria também novas estruturas de oportunidades, que são substancialmente diferentes das bases da participação convencional e não convencional nos espaços off-line. A rede teria esse poder por ser capaz de reduzir algumas das barreiras da participação, principalmente em relação ao tempo e ao acesso à informação, o que ampliaria o debate político. Nesse sentindo, a internet é vista como parte do espaço público e, desse modo, a ágora poderia ser reproduzida 
virtualmente, trazendo a possibilidade de participação ao cidadão comum, inserindo-o nos processos de deliberação. Assim, no ciberespaço seria possível criar uma "democracia forte" que conta com a participação de todos. Portanto, para os ciberotimistas, a internet é capaz de mobilizar indivíduos que não se mobilizavam, fortalecer a democracia e, desse modo, suavizar as clivagens sociais do mundo offline (Boulainne, 2009; NORRIS, 2001; NORRIS; CuRTICE, 2006; XenOS; MOY, 2007).

Como desdobramento dessa abordagem, a relação entre a internet e o engajamento pode ser pensada como um efeito instrumental. De acordo com essa perspectiva, a rede reduz os custos do engajamento ao aumentar a possibilidade de acesso a diferentes informações. Portanto, a lógica desse argumento é que o aumento e a diversidade de informações disponíveis favorecem o maior engajamento, mesmo que o indivíduo em questão seja apático nas modalidades de participação off-line e não possua forte interesse por política, já que essa orientação cognitiva pode ser criada no ciberespaço. O otimismo reside na crença de que o simples fato de o acesso à tecnologia levar ao engajamento implica na suposição de que a relação ocorre em apenas uma direção, da tecnologia para o engajamento (XENOS; MOY, 2007).

Os ciberpessimistas, por sua vez, acreditam que a internet reforça as estruturas que já estão postas e, por conseguinte, não é uma ferramenta revolucionária, principalmente porque o acesso à tecnologia é quase exclusividade dos indivíduos e países com altos níveis socioeconômicos. Além disso, a rede não seria capaz por si só de despertar o interesse político e, dessa maneira, o ativismo on-line seria mais uma modalidade de participação para aqueles que já são engajados no mundo off-line. Portanto, para os ciberpessimistas, as novas tecnologias da informação não teriam a capacidade de transformar a sociedade e atuariam no sentindo de aprofundar as clivagens sociais já existentes (NORRIS, 2001; NoRRIS; CURTICE, 2006).

Elucidativa da visão pessimista é a hipótese de que o uso político da internet é um efeito de seleção. Para essa interpretação, o indivíduo que irá usar os recursos políticos oferecidos pela rede já estava interessado em assuntos públicos e políticos antes de usar a ferramenta, enfatizando a importância da motivação no engajamento cívico e das predisposições anteriores, como o conhecimento e interesse por política. Assim sendo, a lógica da relação tem um sentido oposto às anteriores, uma vez que o fato de o indivíduo já ser engajado nos espaços off-line é que levaria ao uso político da tecnologia. Portanto, para esse modelo explicativo, as novas tecnologias de informação e comunicação simplesmente trazem novas oportunidades para os cidadãos já ativos (NORRIS, 2001). 
Para além dos pessimistas estão os cibercéticos, que também não acreditam na possibilidade de a rede transformar indivíduos desinteressados politicamente em pessoas interessadas, mas que adicionalmente argumentam que não está entre as habilidades da internet mudar o status quo político e social, já que a mesma se adapta aos sistemas políticos e sociais existentes, sem criar outras estruturas de oportunidades ou modificar as mesmas. Portanto, para os cibercéticos, o ciberespaço apenas reproduz a política como de costume, sem eliminar ou aprofundar as clivagens sociais existentes (NORRIS, 2001; NORRIS; CURTICE, 2006).

As perspectivas apresentadas até o momento procuram explicar a relação entre internet e engajamento cívico de uma maneira unidirecional. Entretanto, existem outras vertentes que enfatizam diferentes causas para o ativismo on-line, sendo necessário olhar por dimensões macro e micro da sociedade, a fim de sustentar a suposição de que o fenômeno é multidirecional. Questões estruturais do Estado e da sociedade, como o desenvolvimento socioeconômico e o desenho das instituições políticas e sociais, correspondem à dimensão macro. Já o nível micro destaca os recursos e motivações individuais (BEST; KRUEGER, 2005; HAFNER-FINK; OBLAK ČRNIČ, 2014; NORRIS, 2001).

Assim sendo, a dimensão dos recursos (VERBA; SCHLOZMAN; BRADY, 1995) se mostra útil para a perspectiva multidirecional, pois, como já discutido anteriormente, no modelo do voluntarismo cívico, os autores demonstram que a participação política é estratificada pelos recursos de tempo, dinheiro e habilidades cívicas, além de ser influenciada pelas motivações individuais. Esses aspectos podem ser combinados indiscriminadamente, de acordo com as necessidades da ação política, portanto, também se mostram profícuos para debater o uso político da internet. Entretanto, como argumentam Best e Kruger (2005), é preciso ter em conta que, para a participação off-line, as habilidades cívicas têm mais impacto que os recursos físicos e que tal característica pode ser invertida para o ativismo on-line. Primeiro, porque a infraestrutura que o país em questão possui, o fato de o indivíduo ter acesso à internet em casa ou no smartphone e a velocidade da conexão são crucias para facilitar a participação na internet, mas também porque as capacidades necessárias para atuar na rede são distintas, de modo que, para o uso efetivo do ciberespaço, são necessárias algumas habilidades técnicas.

O impacto da internet no engajamento também pode ser analisado como um efeito psicológico que combina as características psicossociais do indivíduo, levando em consideração seu contexto social e os motivos que o levam a estar online. Assim, "[...] the psychological approach not only assumes that different kinds of individuals use media for different reasons but also predicts that the effects of such use will differ depending on a number of factors" (XENOS; MOY, 2007, p.708). 
Portanto, para essa perspectiva, existe um processo interativo do usuário com a tecnologia, o que demonstra seu caráter multidirecional.

No modelo de engajamento on-line desenvolvido por Pippa Norris (2001), o uso político da rede é um produto da combinação entre a tecnologia de comunicação mediada por computadores e sua particularidade interativa, o meio socioeconômico e o sistema político virtual que se forma como um reflexo do mundo off-line, pois utiliza o sistema convencional como modelo. No meio virtual, a sociedade civil expressa suas demandas através de grupos de interesse, novos movimentos sociais e partidos políticos que têm como função levar essas demandas para o espaço público a fim de que cheguem ao Executivo e Legislativo com o objetivo de influenciar a agenda política. O Estado, por sua vez, canaliza as informações aos cidadãos com o intuito de dar uma resposta (BOULIANNE, 2009; NORRIS, 2001).

Seguindo o modelo do sistema político off-line, o sistema político on-line poderia ser apenas uma reprodução do "original". Entretanto, as estruturas de oportunidades diferem nos dois espaços, e, muito embora os recursos e motivações, centrais no modelo do voluntarismo cívico, também se mostrem importantes para o ciberespaço, o fato de a ação ocorrer por meio de um computador e da tecnologia de comunicação mediada por ele modifica as oportunidades. Desse modo, é possível falar do surgimento de uma cibercultura que perpassa o ativismo on-line, pois "[the] cyber-society is a place of choice par excellence so that where people go and what they do is likely to be strongly channeled by their prior preferences and interests [...]" (NoRRIS, 2001, cap. 10, p. 2).

A autora ainda argumenta que, devido ao grande peso da individualidade, o uso político da rede pode ser visto como revolucionário ou reforçador. É revolucionário à medida que se apresenta como um espaço em que os novos movimentos sociais, aqueles que possuem uma grande simpatia por valores pós-materialistas, podem se fortalecer e exercer influencia sobre os valores e atitudes da sociedade. Desse modo, a internet pode contribuir no longo prazo para uma maior transformação da opinião pública. Entretanto, por ser a mídia da escolha, o uso da rede depende diretamente do indivíduo, e, nesse sentido, no primeiro momento, a web é reforçadora, pois são os gostos e preferências individuais que norteiam o uso. Consequentemente, são dois movimentos executados pelo ciberespaço que podem reforçar as estruturas e valores consolidados, mas que também servem como meio de contestação das estruturas e mudança de valores (NORRIS, 2001).

Portanto, para essa autora, os usos políticos da rede seriam mais bem explicados pela teoria do círculo virtuoso, segundo a qual as mídias em geral são incapazes de envolver novos participantes no processo político, possuindo então o mérito 
de ativar ainda mais os já engajados, aumentando as suas possibilidades de ação em um processo de mútuo reforço gerado pelo círculo virtuoso em que o ativista está imerso. Nesse sentido, a internet ainda teria um efeito semelhante sob os desengajados, ao passo que é capaz de mantê-los alheios às suas potencialidades políticas, primeiramente porque esses indivíduos não estão predispostos a procurar informações políticas na rede, mas também porque ao encontrarem essas informações não dariam atenção devido à sua falta de interesse e, se por acaso derem atenção às informações, provavelmente duvidem da credibilidade da mesma. Portanto, a web pode aprofundar as divisões entre os apáticos e os engajados, principalmente porque a internet é considerada, por excelência, a mídia da escolha (NORRIS, 2001).

Apesar de considerável pessimismo inerente nessa tese do abismo crescente entre os mobilizados e os desmobilizados, o modelo de engajamento na internet sugere que a cibercultura apresenta particularidades importantes que podem contribuir para um processo de mudança de valores. Entretanto, não podemos esperar essa mudança de valores entre os cidadãos adultos da sociedade em que vivemos, pois, como já foi demonstrado, a cultura e os valores estão intrinsecamente relacionados ao processo de socialização primária e secundária do individuo, portanto, pode esperar alterações apenas com a mudança geracional. O modelo de Norris (2001) ainda sugere que a rede pode alterar a política tradicional: “ [...] by altering the balance of resources among the political institutions, reducing the costs of gathering information and communicating messages, with consequences that will mainly serve to benefit minor parties, smaller groups and fringe movement activists" (NoRRIS, 2001, cap. 12, p. 06).

Em paralelo a essas discussões acerca dos efeitos do ativismo on-line sobre o presencial, alguns trabalhos recentes têm identificado o surgimento de formas essencialmente digitais de ação política e sugerido a necessidade de um esforço classificatório do engajamento on-line que ocorre nesse novo local que é o ciberespaço (BARBER, 2003; HAFNER-FInK; OBLAK ČRNIČ, 2014; NoRRIS, 2001).

Hafner-Fink e Oblak Črnič (2014) argumentam que atualmente existem três grandes grupos de ativistas: aqueles que só participam em modalidades presenciais; os que participam em modalidades off-line e on-line; e os ciberativistas, denominados pelos autores de cidadãos digitais por só atuarem no ciberespaço. Diante desse quadro de múltiplas possibilidades de ação política, os pesquisadores se basearam na classificação das modalidades participativas presenciais propostas por Barnes e Kaase (1979) e defendem que as modalidades de ação na web podem ser divididas também em convencionais e não convencionais. 
São classificadas como formas de participação política digital convencional as ações que ocorrem no contexto institucional, como voto on-line, acesso a website de partidos, políticos e movimentos sociais ou então o ato de seguir um político pelo Facebook e as formas de comunicação em meios digitais, como, por exemplo, mandar um e-mail para entrar em contato com um político. Já as atividades políticas digitais não convencionais envolveriam protestos e mobilizações on-line, construção de fóruns de debate, de associações e/ou grupos de interesse on-line, entre outras, já que o dinamismo e a criatividade nesse grupo são expressivos. É importante ressaltar que as ações na rede podem ser exclusivamente on-line como podem se articular com ações off-line (HAFNER-FINK; OBLAK ČRNIČ, 2014). ${ }^{1}$

Testes empíricos interessantes sobre as hipóteses acerca da relação entre ativismo on-line e presencial também já podem ser localizados nessa agenda de investigações. Norris (2001), por exemplo, usando dados do Eurobarômetro, demonstra que a população on-line era mais participativa nas modalidades tradicionais que os desconectados, além de serem mais jovens, mais escolarizados e com maior renda. Existiria uma clivagem de gênero também nesse ambiente virtual, já que homens participam mais; e também ocupacional, uma vez que indivíduos com cargos gerenciais também predominam no ciberespaço. Em termos atitudinais, essa comunidade europeia on-line era formada por cidadãos mais informados e conhecedores dos assuntos políticos, além de apresentarem valores pós-materialistas, serem mais confiantes nas instituições políticas e prezarem a participação democrática e o cosmopolitismo.

Nesse campo empírico, merece destaque também o trabalho de Best e Kruger (2005), que, se ocupando dos recursos necessários ao ativismo on-line, identificam que eles são distintos dos exigidos na participação presencial e também que a mobilização off-line não implica em ciberativismo. A conclusão mais importante desses autores, entretanto, diz respeito à confirmação da hipótese de que a mobilização on-line favorece algumas formas específicas de participação off-line, ao menos no que se refere à população norte-americana analisada. Os testes demonstram que as habilidades cívicas não têm a mesma relevância para o ativismo on-line, entretanto, conhecimentos e competências com a internet se mostraram altamente influentes, superando o interesse por política, uma das forças motrizes de qualquer ação política. $O$ recurso de tempo, que é central para as modalidades

\footnotetext{
${ }^{1}$ De acordo com pesquisa realizada pela Fundação Perseu Abramo na cidade de São Paulo, no dia 15/03/2015, durante a manifestação contra a corrupção e a favor do impeachment, 75\% dos manifestantes afirmaram que foram chamados via redes sociais e destes $52 \%$ receberam a convocatória via facebook. Esses dados indicam para o crescimento do uso das redes sociais digitais para articular ações presenciais.
} 
presenciais, também não apresentou significância para o ativismo on-line. A pesquisa ainda indica que o acesso à internet em casa e conexões mais rápidas não influenciam o ativismo digital, revelando que as motivações individuais continuam sendo as mais importantes. Por fim, identifica que o ativismo on-line tem uma leve influência na probabilidade de entrar em contato com um agente público e que existe alta correlação entre as habilidades cívicas e aquelas relacionadas ao uso da internet, o que indica que indivíduos que possuem os recursos para o ciberativismo também possuem os recursos da participação presencial (BEST; KRUEGER, 2005).

Em um estudo realizado com os britânicos, Norris e Curtice (2006) analisaram as relações entre o ativismo on-line e off-line, partindo da premissa de que as características políticasesociais dointernauta impactam diretamentenociberativismo e que esse fenômeno participativo possui uma natureza multidimensional. Diante disso, as análises demonstram que os indivíduos com maiores níveis educacionais, os mais jovens e os com amplo acesso à informação são os mais ativos on-line. $A$ pesquisa conclui que o impacto potencial da internet na participação democrática reside na promoção das atividades cívicas e nas cause oriented, fortalecendo os grupos de interesse e os movimentos sociais, principalmente aqueles chamados de novos. Esses dados apresentam algumas possibilidades e limites dos aspectos normativos elencados anteriormente, de acordo com os autores:

“[...] the argument developed in this study rejects the view that everything will change as the Internet facilitates radical forms of direct democracy that come to replace the traditional channels of representative governance (as optimists originally hoped). Nor do we accept that the digital divide will inevitably reinforce existing socio-economic and demographic disparities in political activism (as pessimists predicted). The alternative view that nothing will change as the digital world merely replicates "politics as usual" (as the skeptics suggest) also seems implausible. Instead the argument developed here suggests that we need to understand the multidimensional nature of political activism and how this interacts with the characteristics of Internet users. We predict that certain dimensions of activism will probably be strengthened by the rise of the knowledge society, particularly cause-oriented forms of political participation, reflecting the prior social and political characteristics of the on-line population" (NORRIS; CURTICE, 2006, p. 6-7).

Xenos e Moy (2007), por sua vez, fizeram um estudo com a população estadunidense no ano de 2004 durante a campanha eleitoral, procurando traçar um perfil dos internautas que usaram a rede politicamente, e encontraram que os mais jovens e com altos níveis educacionais e de renda são os mais ativos. A pesquisa 
também procurou evidências que explicassem a participação on-line dialogando com as hipóteses do efeito instrumental e do efeito psicológico. Os resultados mostraram que a ação on-line é um efeito instrumental, ou seja, a tecnologia leva ao engajamento, pois os norte-americanos utilizaram a internet rotineiramente durante as eleições de 2004 com o intuito de reduzir as incertezas em relação aos candidatos funcionando como uma fonte de informação. Nesse sentido, o efeito instrumental se expressa nos processos de aquisição e uso das informações.

Contudo, entre os estadunidenses, o ciberativismo também apresenta um componente psicológico, uma vez que depende das características psicossociais do internauta, como o interesse político. Assim, a internet possui uma força positiva para a cidadania democrática, pois amplia o acesso à informação e apresenta novos repertórios para a ação. Por outro lado, os resultados também evidenciam que o ativismo on-line é praticado por cidadãos que já estão predispostos a tal comportamento, e, nesse sentido, a rede mundial de computadores tem potencial para aumentar as lacunas existentes entre engajados e desengajados (XENOS; MoY, 2007).

Brundidge e Rice (2009) chegaram a conclusão semelhante acerca da população estadunidense, identificando que a internet reforça a atividade daqueles que já estavam envolvidos em ações presenciais.

Para o contexto latino-americano, o trabalho de Schegel (2009) apresenta evidências bastante interessantes sobre esse tema a partir da identificação do perfil do internauta argentino, brasileiro e chileno em termos de participação e valores políticos, usando dados do Latinobarômetro de 2007. Devido à ausência de variáveis que medissem o ciberativismo, o autor se propôs a analisar os impactos de características sociodemográficas, comportamentais, associativismo e exposição à mídia tradicional no acesso regular à internet. Segundo o estudo, o internauta brasileiro é mais educado, mais jovem, interessado em política, pertence a associações esportivas, de lazer ou cultural e tem por hábito a leitura de jornais. Já no caso da Argentina, o usuário da internet possui maiores níveis educacionais, maior renda e é trabalhador gerencial. O pertencimento a sindicatos e a exposição à mídia tradicional, rádios e jornais especificamente, também se mostram influentes sobre o uso regular da tecnologia. No caso do Chile, indivíduos mais educados, mais ricos, mais jovens, que atuam em cargos gerenciais, brancos e interessados em política são mais propensos a utilizarem o ciberespaço regularmente; os chilenos são os únicos para os quais a exposição a outras modalidades midiáticas não se mostrou significante.

Nos três países, viver em cidades com mais de 100 mil habitantes aumenta as chances de uso da tecnologia digital. Outra característica dos internautas da região 
é que eles são mais participativos que o restante da população. No que se refere aos valores, os internautas dos três países se mostraram um pouco mais críticos em comparação à população em geral. No Brasil, o internauta confia menos no Congresso, no governo e na Igreja e confia mais nas empresas privadas. Esses indivíduos que utilizam a internet são mais sensíveis às desigualdades de renda e mais tolerantes em relação ao aborto. Os internautas argentinos são mais democráticos, mais tolerantes ao aborto e também confiam menos na Igreja, no Congresso e nas Forças Armadas. Por fim, no Chile os internautas são mais liberais, confiam mais nas empresas privadas, são mais tolerantes ao aborto e também confiam menos na Igreja (SCHEGEL, 2009).

Diante desses dados, Schegel (2009) conclui que, nas recentes democracias ao sul da América, apesar das características elencadas e de uma maior criticidade em relação às instituições democráticas, o internauta não se diferencia substancialmente do restante da população. Nesse sentido, a internet se apresenta, em um primeiro momento, como um mecanismo que auxilia no aumento do volume da voz daqueles que já possuíam vantagens no espaço público, mas é preciso relativizar a magnitude da digital divide em contextos como os apresentados, já que não há grandes diferenciações entre os conectados e os desconectados.

\section{Relações entre ativismo on-line e presencial}

Para analisar as possíveis relações entre o ativismo político que se dá na rede e o que ocorre presencialmente nas instituições e espaços públicos, a pesquisa cujos resultados apresentamos neste artigo se utilizou da base de dados do Projeto de Opinião Pública na América Latina (Lapop) em sua edição de 2012 para o Brasil. Essa edição foi a única que incluiu uma bateria de três questões que trata especificamente do engajamento político on-line dos cidadãos brasileiros. Essas questões interrogam os entrevistados sobre o compartilhamento de conteúdos políticos por meio das redes sociais; sobre o acesso a sites de políticos, partidos ou movimentos políticos; e também sobre a sua participação em listas de e-mails com conteúdo político². Como já é sabido dos usuários do Lapop, o questionário também contempla questões sobre outras várias formas de atuação política convencionais

\footnotetext{
${ }^{2}$ Variáveis de Participação Online: Acesso a sites de partidos, movimentos ou políticos: (BRAWWW2). Nos últimos doze meses o sr. /sra. visitou o sítio na internet de algum partido político, algum político ou alguma organização política? (1) Sim (2) Não / Compartilhar informações políticas em redes sociais: (PROT8). Nos últimos doze meses, o(a) sr. /sra. leu ou compartilhou informações políticas em alguma rede social na internet como Twitter, Facebook ou Orkut? (1) Sim (2) Não / Participação em lista de e-mails: (BRAWWW3). Nos últimos doze meses o sr. /sra. participou em alguma lista de e-mails que discutiu algum tema político? (1) Sim (2) Não. Todas as variáveis tiveram sua codificação original alterada para (0) Não e (1) Sim.
} 
e também contestatórias ${ }^{3}$. Dessa forma, foi possível verificar em que medida o ativismo político on-line se relaciona com o engajamento presencial por meio de diferentes modelos estatísticos.

A primeira informação relevante pode ser obtida com a identificação das frequências percentuais dessas distintas modalidades. Foram incluídas as três variáveis relativas ao ambiente virtual e também o contato com lideranças políticas locais, a participação em reuniões de partidos ou movimentos políticos, o envolvimento em protestos e manifestações, a participação em associações comunitárias e o trabalho em campanha eleitoral. Algumas outras formas relevantes, como o envolvimento em boicotes ou bloqueios de tráfego não foram incluídas em razão do baixo número de indivíduos envolvidos nessas atividades, o que inviabilizaria as análises multivariadas que apresentamos na sequência. Podemos verificar que os brasileiros ativam os diferentes repertórios de participação nos espaços on-line e off-line em frequências similares, em nenhum dos casos chegando a $15 \%$ da população ativa (Tabela 1 ).

\section{Tabela 1 - Participação política entre brasileiros (\%)}

\begin{tabular}{l|l}
\hline On-line & Sim \\
\hline Acesso a sites de partidos, movimentos ou políticos & 8,7 \\
Compartilhar informações políticas em redes sociais & 10,8 \\
Participação em lista de e-mails & 6,8 \\
\hline Off-line & Sim \\
\hline Contato com autoridades locais & 11,2 \\
Participação na comunidade & 13 \\
Participação em partidos ou movimentos sociais & 3,3 \\
Participação em protestos ou manifestações & 4,7 \\
Trabalho em campanha & 11,8 \\
\hline
\end{tabular}

Fonte: Lapop (2012).

\footnotetext{
${ }^{3}$ Variáveis de Participação Presencial: Contato com autoridades locais: (NP2). O(A) sr. /sra solicitou ajuda ou enviou pedido a algum vereador, funcionário ou órgão da prefeitura nos últimos doze meses? (1) Sim (2) Não / Participação em partidos ou movimentos políticos: (CP13). Reuniões de um partido ou movimento político? Assiste às reuniões dessas organizações: (1) Pelo menos uma vez por semana, (2) Uma ou duas vezes ao mês, (3) Uma ou duas vezes ao ano, ou (4) Nunca? / Participação em protesto ou manifestação: (PROT3). Nos últimos doze meses, o(a) sr. /sra. participou de alguma manifestação ou protesto público? (1) Sim (2) Não / Participação na comunidade: (CP8). Reuniões de uma associação de bairro ou junta de melhorias para a comunidade? Assiste às reuniões dessas organizações: (1) Pelo menos uma vez por semana, (2) Uma ou duas vezes ao mês, (3) Uma ou duas vezes ao ano, ou (4) Nunca? / Trabalho em campanha: (PP2). Existem pessoas que trabalham para algum partido ou candidato durante as campanhas eleitorais. $\mathrm{O}(\mathrm{A})$ sr. /sra. trabalhou para algum partido ou candidato nas eleições presidenciais de 2010? (1) Sim (2) Não. Todas as variáveis tiveram sua codificação original alterada para (0) Não e (1) Sim.
} 
O primeiro modelo multivariado foi proposto para identificar possíveis convergências entre as diferentes modalidades pela identificação de suas variações conjuntas por meio da técnica de análise fatorial (HAIR et al., 1984). Como todas as variáveis apresentam codificação dicotômica ( 0 e 1 , sendo esse último igual à participação), a análise foi conduzida a partir de matriz de correlação tetracórica (DIGBY, 1983).

Os resultados expostos na Tabela 2 apontam para forte convergência entre as modalidades. Primeiramente, entre o bloco das atividades on-line, as cargas fatoriais próximas de 7 indicam forte comunalidade ou variação conjunta, sustentando a hipótese de que indivíduos que se utilizam de uma das formas, tendem também a praticar as outras duas. A ligação, entretanto, se mantém quando avançamos para o bloco das modalidades presenciais, já que apenas em um dos casos (participação comunitária) a carga no primeiro fator foi inferior a 5 (Hair et al., 1984). Dessa forma, não parece existir clara distinção no nível empírico entre as modalidades de ativismo que ocorrem no ambiente virtual e no presencial, já que os ativistas de um ambiente tendem também a se comportar de forma ativa no outro. Assim, como trabalhos anteriores afirmaram quanto à convergência entre modalidades convencionais e contestatórias (RIBEIRO; BORBA, 2015), quando a oposição se dá entre formas on-line e off-line, algo semelhante parece ocorrer.

\section{Tabela 2 - Análise fatorial com modalidades de participação on-line e presencial}

\begin{tabular}{lll}
\hline Variáveis & Fator 1 & Fator 2 \\
\hline Acesso a sites de partidos, movimentos ou políticos &, 704 &,- 375 \\
$\begin{array}{l}\text { Compartilhamento de informações políticas em redes } \\
\text { sociais }\end{array}$ &, 692 &,- 303 \\
Participação em lista de e-mails &, 796 &,- 304 \\
\hline Presencial & & \\
\hline Contato com autoridades locais &, 511 &, 314 \\
Participação na comunidade &, 483 &, 295 \\
Participação em partidos ou movimentos sociais &, 733 &, 389 \\
Participação em protestos ou manifestações &, 597 &,- 125 \\
Trabalho em Campanha &, 507 &, 398 \\
\hline
\end{tabular}

Fonte: Lapop (2012).

Feita essa análise inicial com cada uma das variáveis de forma independente, para conduzir os testes multivariados, optamos por unir as três formas de ativismo na rede em um índice de ativismo on-line. Os resultados da fatorial tetracórica anterior já indicavam a pertinência dessa redução de dimensionalidade, mas adicionalmente 
também conduzimos o teste de confiabilidade de Alfa de Crombach, que resultou em 0,617, dentro dos parâmetros estabelecidos pela literatura (Hair et al., 1984). Por procedimento somatório, sem pesos diferentes para cada variável, esse índice compôs uma escala de 0 a 3, em que 0 significa a não participação em nenhuma das formas de ativismo on-line (inativo), 1 se refere à participação em apenas uma das modalidades (pouco ativo), 2 à participação em duas modalidades (ativo) e 3 significa a participação em todas as formas de ativismo on-line (muito ativo). A Tabela 3 apresenta a distribuição dos componentes da amostra nessa medida integrada e revela uma grande maioria de inativos.

Tabela 3 - Índice ativismo on-line

\begin{tabular}{l|l}
\hline Índice de ativismo on-line & Frequência \\
\hline Não é ativo & $78,3 \%$ \\
Ativo em uma categoria & $13,8 \%$ \\
Ativo em duas categorias & $5,3 \%$ \\
Ativo em três categorias & $2,6 \%$ \\
Total & $100,0 \%$ \\
\hline
\end{tabular}

Fonte: Lapop (2012).

Como esse índice não apresenta distribuição aproximadamente normal e dificilmente pode ser considerada uma medida contínua em razão da sua curta escala, para identificar quais são os condicionantes do engajamento on-line optamos pela construção de um modelo de regressão logística multinominal, que considera a medida qualitativa e toma como categoria de referência os inativos, em razão da sua maioria. Sendo assim, todos os coeficientes se referem ao efeito das variáveis independentes sobre a probabilidade de fazer parte de um dos três grupos de ativos, na comparação com a probabilidade de ser inativo. Como possíveis preditores, selecionamos variáveis que são comumente utilizadas para explicar as formas de participação presencial pela literatura. Em termos demográficos foram incluídas as variáveis sexo, anos de estudo e idade. As expectativas para esse primeiro conjunto de testes, apoiados nas teses da centralidade social, são de que homens mais escolarizados apresentem maior tendência de ativismo e que os mais jovens, pela familiaridade com a tecnologia, também apresentem maior engajamento. No que diz respeito aos recursos cognitivos, foram incluídas variáveis sobre o acesso à informação e o nível de conhecimento sobre política. Entendendo que recursos cognitivos são fundamentais para o envolvimento político também no espaço on-line, nossa hipótese inicial é de que os mais informados e que apresentam maior conhecimento específico sobre política sejam os mais ativos. 
No campo das atitudes, foram incluídas as variáveis eficácia política subjetiva, interesse por política e autoposicionamento ideológico. As hipóteses aqui são menos diretas, já que apenas no caso do interesse é plausível supor uma relação direta com o envolvimento. No caso do posicionamento ideológico não é possível afirmar antecipadamente se pessoas localizadas mais à direita ou mais à esquerda seriam mais ativas, já que as ferramentas disponibilizadas pela rede mundial de computadores serviriam aos propósitos políticos mais variados de todos os matizes do espectro ideológico. Mais difícil ainda foi antecipar os efeitos da eficácia política subjetiva, já que o ambiente virtual ao mesmo tempo possibilita maior exposição daqueles que se identificam e também viabiliza o anonimato daqueles que preferem não se identificar. Sendo assim, alguém que avalia como baixa a sua capacidade para influenciar as decisões políticas pode encontrar na rede uma forma de manifestação sem a necessidade de se expor publicamente. Por outro lado, alguém que avalia de forma muito positiva essa mesma capacidade pessoal pode encontrar na internet uma forma de superexposição que potencializa o efeito da sua interferência. ${ }^{4}$

Os resultados apresentados na Tabela 4 de uma forma geral confirmam as hipóteses derivadas do modelo do voluntarismo cívico (VERBA; SCHLOzMAN; BRADY, 1995), especialmente no que se refere ao contraste entre os mais ativos e a categoria de referência dos inativos. Chama a atenção o fato de apenas o interesse por política afetar todas as categorias e com efeito crescente na medida em que se avança no ativismo. Lembrando que essa variável é composta por uma escala de quatro pontos, cada elevação produz elevação de mais de $70 \%$ na probabilidade de

\footnotetext{
${ }^{4}$ Variáveis de recursos sociodemográficos e atitudinais: Acesso a informação política: (GI0). Agora gostaríamos de saber quanta informação sobre política e sobre o país é transmitida para a população. Com que frequência o sr. /sra. presta atenção às notícias, seja na TV, rádio, jornais ou na internet? (1) Diariamente (2) Semanalmente (3) Mensalmente (4) Raramente (5) Nunca. Codificação invertida para (0) Nunca (1) Raramente (2) Mensalmente (3) Semanalmente e (4) Diariamente / Anos de estudos: (ED). Qual foi o último ano de escola que o(a) sr./sra. terminou? / Conhecimento Político: (GI4). De quanto tempo é o mandato do Presidente no Brasil? (1) Correto (2) Incorreto. Codificação invertida para (0) Incorreto e (1) Correto / Eficácia Subjetiva: (EFF1). Os que governam o País se interessam pelo que pessoas como o(a) sr./sra. pensam. Até que ponto concorda ou discorda dessa frase? (1) Discorda muito a (7) Concorda muito. Recodificada para (0) Discorda muito a (6) Concorda muito / Ideologia: (L1) Agora, para mudar de assunto. Nesse cartão há uma escala, de 1 a 10, na qual o número 1 significa "esquerda" e o 10 significa "direita". Hoje em dia, quando se conversa de tendências políticas, fala-se de pessoas que simpatizam mais com a esquerda e de pessoas que simpatizam mais com a direita. De acordo com o sentido político que os termos "esquerda" e "direita" têm para o(a) sr./sra, onde o(a) sr./sra. se situa nesta escala? Recodificada para (0) Esquerda à (9) Direita. / Interesse por Política: (POL1). O quanto o(a) sr./sra. se interessa por política: (1) Muito, (2) Algo, (3) Pouco ou (4) Nada? Codificação invertida para (0) Nada, (1) Pouco, (2) Algo, (3) Muito. (Q1) Sexo: (1) Homem (2) Mulher. Codificação invertida para (0) Mulher (1) Homem.
} 
fazer parte do grupo dos pouco ativos. Sobre a chance de estar entre os ativos, esse efeito é de mais de $117 \%$, tomando como referencia a probabilidade de ser inativo. Sobre a chance de ser muito ativo, a elevação ultrapassa os 360\%. Esses resultados parecem indicar que a dimensão mais importante para o ativismo on-line no cenário nacional é a orientação psicológica positiva para a política. A explicação para esse efeito generalizado pode residir na redução dos custos para a participação operada pela internet, principalmente em termos de tempo, deslocando então a causa para dimensões não ligadas aos recursos.

A eficácia política subjetiva se mostrou preditora relevante para os grupos dos ativos e muito ativos, entretanto o seu efeito foi negativo, inclusive com impacto crescente na categoria dos mais ativos. Isso representa novidade significativa quando consideramos o conjunto das pesquisas na área que não tem encontrado evidências sobre a relevância dessa variável para diferentes modalidades presenciais (RIBEIRO; BORBA, 2015). O que esse resultado indica é que o ativismo on-line é mais frequente entre aqueles indivíduos que avaliam negativamente sua capacidade de intervenção na vida política nacional. Nesse sentido, pode-se realizar uma avaliação otimista sobre o potencial mobilizador da rede, já que tais cidadãos pouco eficazes estariam encontrando nesse ambiente virtual um caminho para sua inserção no debate sobre questões políticas.

Todas as demais variáveis apresentaram efeitos estatisticamente significativos apenas em um grupo ou outro. É o caso do autoposicionamento, que atingiu o nível mínimo de significância apenas para o grupo dos pouco ativos, indicando que quanto mais à direita menor a chance de fazer parte do grupo dos pouco ativos. Nos grupos dos ativos e dos muito ativos, portanto, podemos afirmar que o posicionamento nessa escala não é relevante e que cidadãos com orientações distintas tendem a se comportar de forma semelhante no que diz respeito ao ativismo político on-line.

A dimensão dos recursos, todavia, não foi descartada a partir dos resultados encontrados, pois duas variáveis ligadas ao nível cognitivo se mostraram importantes justamente no grupo dos mais ativos. Cada ano de estudo impacta positivamente em $19,5 \%$ a probabilidade de fazer parte desse grupo, comparada com a probabilidade de ser inativo. Efeito igualmente relevante foi constatado para a variável de acesso à informação, ampliando em mais de $160 \%$ a probabilidade a cada elevação de um ponto na sua escala (de 0 a 4). 
Tabela 4 - Condicionantes do ativismo on-line

\begin{tabular}{|c|c|c|c|}
\hline Pouco ativo & & $\operatorname{Exp}(B)$ & Std. Error \\
\hline & Constante & $-3,357$ & $(, 692)^{* * *}$ \\
\hline & Acesso à informação & 1,145 & $-0,118$ \\
\hline & Anos de estudo & 1,147 & $-0,041$ \\
\hline & Conhecimento político & 0,512 & $-0,544$ \\
\hline & Eficácia subjetiva & 0,959 & $-0,068$ \\
\hline & Idade & 0,987 & $-0,01$ \\
\hline & Ideologia & 0,909 & $(, 044)^{*}$ \\
\hline & Interesse por política & 1,748 & $(, 125)^{* * *}$ \\
\hline & Sexo & 1,109 & $-0,218$ \\
\hline \multicolumn{4}{|l|}{ Ativo } \\
\hline & Constante & $-3,672$ & $(1,038)^{* * *}$ \\
\hline & Acesso à informação & 1,194 & $-0,186$ \\
\hline & Anos de estudo & 1,121 & $-0,061$ \\
\hline & Conhecimento político & 0,348 & $-1,037$ \\
\hline & Eficácia subjetiva & 0,771 & $(, 133)^{*}$ \\
\hline & Idade & 0,982 & $-0,015$ \\
\hline & Ideologia & 0,904 & $-0,062$ \\
\hline & Interesse por política & 2,172 & $(, 183)^{* * *}$ \\
\hline & Sexo & 0,631 & $-0,334$ \\
\hline \multicolumn{4}{|l|}{ Muito ativo } \\
\hline & Constante & $-9,784$ & $(2,195)^{* * *}$ \\
\hline & Acesso à informação & 2,669 & $(, 478)^{*}$ \\
\hline & Anos de estudo & 1,195 & $(, 083)^{*}$ \\
\hline & Conhecimento político & 0,863 & $-1,136$ \\
\hline & Eficácia subjetiva & 0,680 & $(, 176)^{*}$ \\
\hline & Idade & 0,986 & $-0,02$ \\
\hline & Ideologia & 0,874 & $-0,089$ \\
\hline & Interesse por política & 4,640 & $(, 287)^{* * *}$ \\
\hline & Sexo & 1,568 & $-0,471$ \\
\hline \multicolumn{4}{|l|}{ N 1.500} \\
\hline \multicolumn{4}{|l|}{ Nagalkerke $=, 210$} \\
\hline$\%$ acerto $=75,8$ & & & \\
\hline
\end{tabular}


A partir do conjunto desses resultados, podemos formular uma descrição dos perfis dos brasileiros ativistas on-line: comparado com um inativo, uma pessoa pouco ativa é mais interessada em política e se encontra ideologicamente à esquerda; nessa mesma comparação, um indivíduo ativo, além de mais interessado em política, também se sente ineficiente; os muito ativos, além de mais interessados e dotados de baixa eficácia subjetiva, também apresentam maior acesso à informação e são mais educados.

\section{Considerações finais}

O artigo buscou analisar os determinantes da participação política on-line, em especial sobre as relações entre tais modalidades de participação e aquelas definidas como off-line. Após uma revisão da literatura sobre o tema, pudemos constatar que essa apresenta interpretações contrastantes sobre a relação entre internet e política, em especial sobre os impactos das tecnologias da informação e comunicação nos padrões de comportamento político.

O efeito de algumas variáveis é semelhante aos identificados na explicação da participação off-line no Brasil, em especial o impacto da escolaridade e do interesse por política. Em outras palavras, o ativismo on-line é maior entre os mais informados e mais escolarizados, da mesma maneira que outras formas de participação política, como o envolvimento em protestos ou a participação em partidos políticos (RIBEIRO; BORBA, 2015).

Por outro lado, os testes também apontam para o efeito negativo do sentimento de eficácia política (para os ativos e muito ativos) sobre o ativismo on-line; efeito esse inverso daquele identificado por outros estudos, nas formas presenciais (RIBEIRO; BORBA, 2015). Tal resultado tem implicações analíticas significativas, pois indica que a participação on-line pode ser um instrumento de ação política de indivíduos portadores de recursos (escolaridade e informação), mas que não percebem eficácia no seu eventual envolvimento em formas presenciais de participação. Talvez por ser uma atividade que envolva menores custos, é possível perceber na internet uma "estrutura de oportunidade" para a participação política de cidadãos que, na ausência desse instrumento de "voz!", preferiam a "lealdade" ou a "saída", para usarmos expressões de Albert Hirshman (HIRSHMAN, 1983).

Também é significativa a ausência de efeito da categoria sexo no ativismo online. Em pesquisas anteriores, verificou-se que, nas modalidades presenciais, convencionais e de protesto, os homens tendem a ser mais participativos. Além disso, dadas as características patriarcais da nossa sociedade, os homens possuem alguns privilégios que os colocam em uma posição central na sociedade. Nesse sentido, essa 
ausência de efeito demonstra uma brecha na teoria da centralidade de repertórios quando pensada para o contexto digital, uma vez que não confirma a desigualdade política entre homens e mulheres encontrada nas modalidades de ação presencial (BORBA, 2012a; GIMENES; RIBEIRO; BORBA, 2014; OKAdO; RIBEIRO, 2015).

Por fim, a idade do indivíduo também não se mostrou relevante para as atividades políticas no ciberespaço, indo na contramão dos resultados encontrados para a participação presencial. Pesquisas mostram que os mais velhos tendem a ser mais interessados em política, a simpatizar mais e se envolver mais na participação em partidos; e os mais jovens apresentam uma pequena tendência a se envolver mais em ações de protesto, principalmente aquelas em que os custos são mais altos como bloqueio de tráfego (BorbA, 2012a; GIMENES; Ribeiro; BorBA, 2014; OKAdO; RiBeiRo, 2015). A ausência de efeito da idade foi surpreendente, uma vez que esperávamos que os mais jovens atuassem mais no mundo on-line devido a suas maiores habilidades com a tecnologia, como demonstram pesquisas realizadas em outros contextos (HAFNER-FINK; Oblak ČRnič, 2014; NORRIS, 2001; NORRIS; CURTICE, 2006).

Para as pesquisas sobre participação política, tais resultados - mesmo que limitados a um único país e ano - apontam para uma importante agenda de pesquisas, em especial no tocante à relação entre recursos e participação. Pois, conforme apontado acima, é possível perceber que, se por um lado a participação on-line não rompe totalmente com as barreiras impostas pelas desigualdades sociais (veja-se o efeito da escolaridade na participação on-line), por outro lado, ela requer uma quantidade menor de habilidades cívicas do que aquela exigida pela participação off-line. Ao diminuir os custos de entrada no envolvimento político, a participação on-line pode servir como um importante instrumento de socialização, com possíveis efeitos futuros positivos sobre a propensão do indivíduo participar em outras modalidades.

\section{Referências bibliográficas}

BARBER, B. Strong democracy: participatory politics for new age. $20^{\text {th }}$ anniversary edition. California: University Of California Press, 2003.

BARNeS, S.H.; KAASE, M. (Orgs.). Political action: mass participation in five Western democracies. Beverly Hills, CA: Sage, 1979.

BAQUERO, M. Capital social como caminho alternativo na construção democrática: reflexões sobre o Brasil. In: NAZZARI, R.K. Temas de ciência política: teoria do conhecimento; metodologia nas ciências sociais; teorias políticas; comportamento político. EDUNIOESTE, Cascavel, 2004. p.193-221

BeST, S.J.; KRUEGER, B. Analyzing the representativeness of internet political participation. Political Behavior, v. 27, n. 2, p. 183-216, Jun., 2005. Disponível online em: <http://www.jstor.org/stable/4500191>. Acesso em: janeiro de 2010. 
BorbA, J.; RIBEIRo, E. Participação convencional e não convencional na América Latina. Revista Latino-Americana de Opinión Pública, v. 1, p. 53-76, 2010.

BORBA, J. Participação política: a centralidade dos repertórios. Revista Debates, Porto Alegre, v.6, n.1, p.123-147, jan-abr. 2012a. Disponível on-line em: <http://seer.ufrgs. br/index.php/debates/article/view/26167/17098>. Acesso em: julho de 2014.

BoRBA, J. Participação política: uma revisão dos modelos de participação. Revista Estado e Sociedade, Brasília, v. 27, n. 2, p. 263-288. maio-ago 2012b Disponível on-line em:<http://www.scielo.br/scielo.php?pid=S010269922012000200004\&script=sci_arttext>. Acesso em: agosto de 2014.

BoulianNe, S. Does internet use affect engagement? A meta-analysis of research. Political Communication, 26:2, p. 193-211, 2009. Disponível on-line em: <http:// dx.doi.org/10.1080/10584600902854363>. Acesso em: janeiro de 2015.

BRUNDIDGE, J.; RICE, R. Political engagement on-line: do the information rich get richer and like-minded more similar. In: CHADWICK, A.; HoWARD, P. The Routledge Handbook of Internet Politics. New York: Routledge, 2009.

CASTELLS, M. A galáxia da internet: reflexões sobre internet, negócios e sociedade. Tradução de Rita Espanha. Lisboa: Fundação Calouste Gulbenkian, 2004.

A sociedade em rede - a era da informação: economia, sociedade e cultura; v. 1. Tradução: Roneide Venancio Majer e Klauss Brandini Gerhardt, 13ạ reimpressão com novo prefácio. São Paulo, SP: Paz e Terra, 2010.

CASTRO, H.C.O.; REIS, F.T. Participação política no Brasil no século XXI: mudanças e continuidades. Teoria e Pesquisa: Revista de Ciência Política, v. 21, n. 2, p. 2033, jul-dez 2012. Dísponivel on-line em: <http://doi.editoracubo.com.br/10.4322/ tp.2012.015>. Acesso em: outubro de 2014.

DALTON, J.; VAN SICKLE, A. The resource, structural, and cultural bases of protest. Publicado por Center for the Study of Democracy CSD, University of California em 08/08/2005. Disponível on-line em: plataforma escholarship <https://escholarship. org/uc/item/3jx2b911>. Acesso em: janeiro de 2015.

DIGBY, P. G. N. Approximating the tetrachoric correlation coefficient. Biometrics, 39, p. 753-757, 1983.

EKMAN, J; AMnA, E. Political participation and civic engagement: towards a new typology. Human Affairs, v. 22, n. 3, p. 283-300, 2012. Disponível em: <https:// inforum.oru.se/PageFiles/14371/Ekman\%20and\%20Amn\%C3\%A5\%202009-1. pdf>. Acesso em: novembro de 2014.

Fundação Perseu Abramo. Projeto Manifestações Março/2015. Disponível on-line em: <http://novo.fpabramo.org.br/content/fpa-lanca-pesquisa-com-perfil-dosmanifestantes-de-marco-de-2015>. Acesso em: abril de 2015.

GIMENES, E.R; RIBEIRO, E. A.; BorBA, J. Simpatia partidária e participação em partidos políticos na América Latina: determinantes individuais e de contexto do partidarismo. In: CONGRESSO DA ASSOCIAÇÃO BRASILEIRA DE CIÊNCIA POLÍTICA, 9., Brasília, 2014. Anais... Brasília: ABCP, 2014. Disponível on-line em: <http:// www.encontroabcp2014.cienciapolitica.org.br/resources/anais/14/1403631303_ ARQUIVO_Gimenes,RibeiroeBorba-ABCP2014.pdf>. Acesso em: dezembro de 2014. 
HAFNER-FINK, M.; OBLAK ČrnIČ, T. Digital citizenship as multiple political participation? Predictors of digital political participation in Slovenia. Teorija in Praska, let. 51, p. 1284-1303, 6/2014. Disponível on-line em: <http://www.fdv.uni-lj.si/docs/defaultsource/tip/tip_06_2014_hafner-fink_idr.pdf?sfvrsn=2> Acesso em: janeiro de 2015. HAIR, et al. Multivariate data analysis. New York: Macmillan Publishing, 1984. HIRSCHMAN, A. De consumidor a cidadão: atividades privadas e participação na vida pública. São Paulo: Brasiliense, 1983.

INGLEhART, R.; Welzel, C. Modernização, mudança cultural e democracia: a sequência do desenvolvimento humano. São Paulo: Francis, 2009.

INGLEHART, R. The silent revolution in Europe: intergenerational change in postIndustrial societies. American Political Science Review, v. 65, n. 4, p. 991-1017, Dec.1971.

INGLEHART, R. A revolução silenciosa na Europa: mudanças intergeracionais em sociedades pós-industriais. Revista Sociologia e Política, Curitiba, v. 20, n. 43, p. 159-191, out. 2012. Disponível on-line em: <http://www.scielo.br/pdf/rsocp/ v20n43/a08v20n43.pdf>. Acesso em: setembro de 2014.

INTERNATIONAL TELECOMMUNICATION UNION (ITU). Mensuring the information society report 2014. Geneva, Switzerland: ONU, 2014. ISBN 978-92-61-15291-8. Disponível on-line em: <http://www.itu.int/en/ITU-D/Statistics/Documents/publications/ mis2014/MIS2014_without_Annex_4.pdf>. Acesso em: janeiro de 2015.

Latin American Public Opinion Project (LAPOP). Disponível on-line em: <http:// www.vanderbilt.edu/lapop/>. Acesso em: 21 de agosto de 2013.

LÉVY, P. A inteligência coletiva: por uma antropologia do ciberespaço. Tradução Luiz Paulo Rouanet. São Paulo, SP: Edições Loyola, 1999.

Miguel, L. F.; Bırolı, F. Caleidoscópio convexo: mulheres, política e mídia. São Paulo: Editora Unesp, 2011.

Milbrath, L. W. Political participation. Chicago: RandMcNally, 1965.

NoRRIS, P. Digital divide: civic engagement, information poverty anda the internet worldwide. Cambridge: Cambridge University Press, 2001. Disponível on-line em: <http://www.hks.harvard.edu/fs/pNORRIS/Books/Digital\%20Divide.htm>. Acesso em: outubro de 2014.

Democratic Phoenix: reinventing political activism. Cambridge: Cambridge University Press, 2002. Disponível on-line em: <https://sites.google. com/site/pippaNORRIS3/publications/books/democratic-phoenix>. Acesso em: maio de 2014.

Political activism: new challenges, new opportunities. In: BoIx; STOKES, D. The oxford handbook of comparative politics. Oxford: Oxford University Press, 2007. p. 628-652. Disponível on-line em: <http://ksghome.harvard.edu/ pNORRIS/ Acrobat/Boix\&stokes-chap26.pdf>. Acesso em: junho de 2014.

NORRIS, P.; CURTICE, J. If you build a political web site, will they come? The internet and political activism in Britain. International Journal of Electronic Government Research, 2(2), p. 1-21, April-July 2006. Disponível on-line em: <http://www.hks.harvard. 
edu/fs/pNORRIS/Articles/Articles\%20published\%20in\%20journals_files/IJEGR\%20 Website\%20NORRIS\%20and\%20Curtice.pdf>. Acesso em: dezembro de 2014.

OKADo, L. A. T.; RIBEIRo, E. A. Condição juvenil e participação política no Brasil. Paraná Eleitoral: revista brasileira de direito eleitoral e ciência política, Curitiba, v. 4, n. 1, p. 53-78, 2015. Disponível on-line em: <http://www.justicaeleitoral.jus.br/ arquivos/tre-pr-parana-eleitoral-2015-volume-4-revista-1-artigo-2-lucas-toshiaki>. Acesso em: maio de 2015.

Putnam, R. Making democracy work. Princeton: Princeton University Press, 1993.

RENNó, L. R. Confiança interpessoal e comportamento político: microfundamentos da teoria do capital social na América Latina. Revista Opinião Pública, Campinas, v. 7, n. 1, p. 33-59, 2001. Disponível on-line em: <http://www.scielo.br/pdf/op/ v7n1/16932.pdf> Acesso em: dezembro de 2014.

Estruturas de oportunidade política e engajamento em organizações da sociedade civil: um estudo sobre a América Latina. Revista Sociologia Política, Curitiba, 21, p. 71-82, nov. 2003. Disponível on-line em: <http://www.scielo.br/pdf/ rsocp/n21/a06n21>. Acesso em: dezembro de 2014.

RIBEIRO, E; BorBA, J. Participação e pós-materialismo na América Latina. Revista Opinião Pública, Campinas (Unicamp), v.16, n. 1, p. 28-63, 2010. Disponível on-line em: <http://www.scielo.br/scielo.php?pid=S0104-62762010000100002\&script=sci_ arttext>. Acesso em: julho de 2014.

RIBEIRO, E. Valores pós-materialistas e cultura política no Brasil. Maringá: Eduem, 2011.

RiBeIRo, E.; BorbA, J. As dimensões da participação política no Brasil. Teoria e Pesquisa: Revista de Ciência Política, São Carlos (UFSCAR), v. 20, p. 11-36, 2011. Disponível on-line em: <http://www.teoriaepesquisa.ufscar.br/index.php/tp/ article/viewFile/261/191>. Acesso em: agosto de 2014.

RibeIRo, E.; BorBA, J. Participação política na América Latina. Maringá: Eduem, 2015. SCHUMPETER, J. A. Capitalismo, socialismo e democracia. Rio de Janeiro, RJ: Zahar, 1984.

SCHLEGEL, Rogério. Internauta brasileiro: perfil diferenciado, opiniões indiferenciadas. Revista de Sociologia e Política, Curitiba, v. 17, n. 34, p. 137-157, out. 2009. Disponível on-line em: <http://www.scielo.br/scielo.php?pid=S010444782009000300011\&script=sci_arttext>. Acesso em: fevereiro de 2014.

VAN DETH, J. Studying political participation: towards a theory of everything? In: ECPR Joint Sessions. Grenoble, France: 2001. Disponível online em: <http://www. academia.edu/2233354/STUDYING_POLITICAL_PARTICIPATION_TOWARDS_A_ THEORY_OF_EVERYTHING>. Acesso em: setembro de 2014.

Verba, S.; SChlozman, K. L.; BrAdy, H. E. Voice and equality: civic voluntarism in American politics. Cambridge, Mass.: Harvard University Press, 1995.

XENOS, M.; MoY, P. Direct and differential effects of the internet on political and civic engajament. Journal of Communication, 57 (International Communication Association), p. 704-718, 2007. Disponível online em: <http://onlinelibrary.wiley.com/doi/10.1111/ j.1460-2466.2007.00364.x/references>. Acesso em: janeiro de 2015. 


\section{Ednaldo Aparecido Ribeiro}

Possui doutorado em Sociologia pela Universidade Federal do Paraná (UFPR). Atualmente é Professor Adjunto da Universidade Estadual de Maringá (UEM). Contato: ednaldoribeiro@icloud.com

\section{Julian Borba}

Possui doutorado em Ciência Política pela Universidade Federal do Rio Grande do Sul (UFRGS). Atualmente é Professor da Universidade Federal de Santa Catarina (UFSC). Contato: julian@cfh.ufsc.br

Jaqueline Resmini Hansen

Doutorado em andamento em Ciência Política na Universidade Federal de Minas Gerais (UFMG). Contato: jaqueline.hansen@live.com 